\title{
Flow Through a Rectangular-to-Semiannular Diffusing Transition Duct
}

\author{
NASA-CR-204816 \\ Jeff Foster* \\ Fisher-Rosemount, Inc., Eden Prairie, Minnesota 55344 \\ Bruce $\mathbf{J}$. Wendt $\dagger$ \\ Modern Technologies, Inc., Cleveland, Ohio 44135 \\ Bruce A. Reichert $\ddagger$ \\ Kansas State University, Manhattan, Kansas 66506 \\ and \\ Theodore H. Okiishi§ \\ Iowa State University, Ames, Iowa 50011
}

\begin{abstract}
Rectangular-to-semiannular diffusing transition ducts are critical inlet components on supersonic airplanes having bifucated engine inlets. This paper documents measured details of the flow through a rectangular-to-semiannular transition duct having an expansion area ratio of 1.53 . Three-dimensional velocity vectors and total pressures at the exit plane of the diffuser are presented. Surface oil-flow visualization and surface static pressure data are shown. The tests were conducted with an inlet Mach number of 0.786 and a Reynolds number based on the inlet centerline velocity and exit diameter of $3.2 \times 10^{6}$. The measured data are compared with previously published computational results. The ability of vortex generators to reduce circumferential total pressure distortion is demonstrated.
\end{abstract}

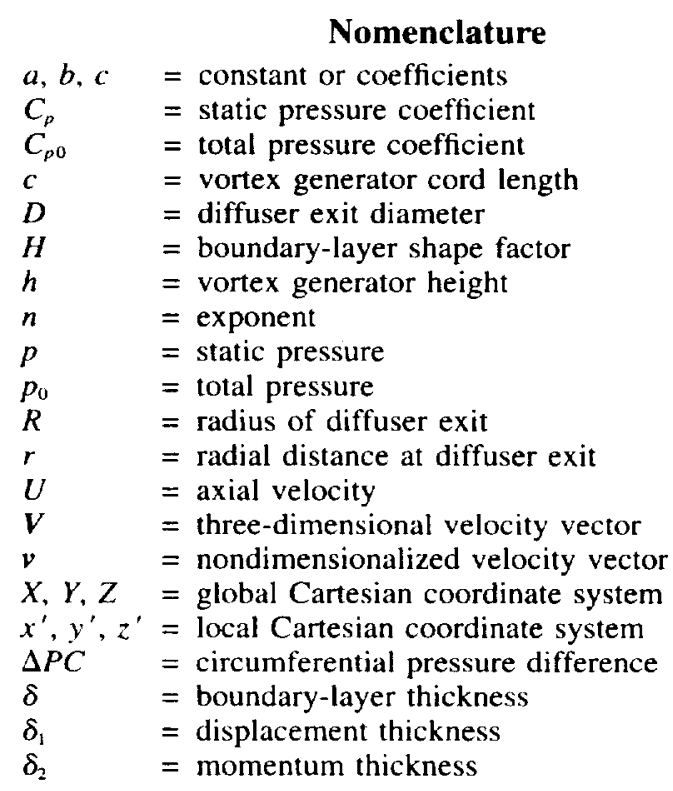

Presented as Paper 96-0448 at the AIAA 34th Aerospace Sciences Meeting, Jan, 15-18, 1996. Reno, NV, 1996; received Feb. 3, 1996; revision received Nov. 12, 1996; accepted for publication Nov. 25, 1996. Copyright (C) 1996 by the American Institute of Aeronautics and Astronautics, Inc. No copyright is asserted in the United States under Title 17, U.S. Code. The U.S. Government has a royalty-free license to exercise all rights under the copyright claimed herein for Governmental purposes. All other rights are reserved by the copyright owner.

*Design Engineer, Measurement Division, Flow Operations Department, 12001 Technology Drive.

$†$ Resident Research Engineer, Inlet, Duct and Nozzle Flow Physics Branch, 21000 Brookpark Road. Member AIAA.

$\$$ Associate Professor, Department of Mechanical Engineering, 302 Durland Hall. Senior Member AIAA.

§associate Dean, Iowa State University, College of Engineering, 104 Marston Hall. Member AIAA.

$$
\begin{array}{ll}
\theta^{-} & =\text {extent of distortion } \\
\tau & =\text { dimensionless axial distance } x / R \\
\text { Subscripts } & \\
\text { av } & =\text { average of a quantity } \\
\text { cl } & =\text { inlet centerline condition } \\
\max & =\text { maximum } \\
0 & =\text { vortex generator width }
\end{array}
$$

\section{Introduction}

D IFFUSING transition ducts are critical components of aircraft propulsion systems. Rectangular-to-semiannular transition ducts are used as the subsonic diffuser portion of bifurcated supersonic inlets. A diagram of a bifurcated inlet can be seen in Fig. 1. The rectangular portion of the duct is located immediately downstream of the normal shock, and the semiannular portion is immediately upstream of the compressor front face.

The primary function of the diffusing transition duct is to decelerate the inlet flow from a Mach number of roughly 0.8 to an airspeed of about Mach 0.4 relative to the compressor front face. This must be done without generating large transverse velocity components and with minimal flow distortions and total pressure losses. Design considerations favor shorter

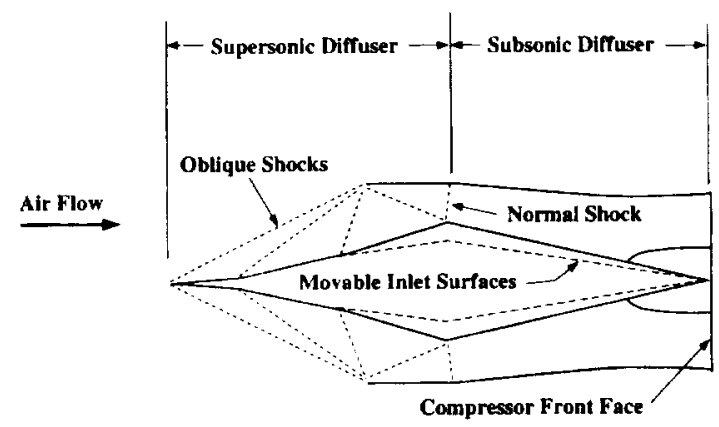

Fig. 1 Schematic of bifurcated inlet. 


\section{Flow Through a Rectangular-to-Semiannular Diffusing Transition Duct J. Foster, B. J. Wendt, B. A. Reichert, T. H. Okiishi}

Reprinted from

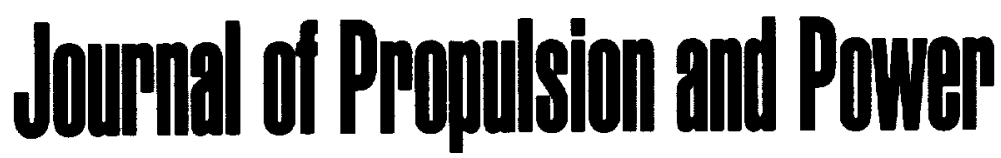

Volume 13, Number 2, Pages 312-317

OAHA솜

A publication of the

American Institute of Aeronautics and Astronautics, Inc.

1801 Alexander Bell Drive, Suite 500

Reston, VA 20191-4344 
diffusers. However, shorter diffusers have larger adverse pressure gradients and more streamline curvature, both of which can cause significant flow distortion, pressure losses, and transverse velocity components to develop.

Tests of a rectangular-to-semiannular diffusing transition duct were conducted by Brown et al. 'In these studies, only total pressure data were taken. Vortex generators were used to eliminate flow separation and improve the pressure recovery of the duct.

An entire supersonic bifurcated inlet was tested by Mealson et $\mathrm{al}^{2}{ }^{2}$ In this study it was determined that there was good symmetry between the two halves of the inlet. This suggests that it is acceptable to test one-half of the inlet and extrapolate these results to the full inlet, at least for low angles of attack.

Anderson and Kapoor ${ }^{3}$ designed a rectangular-to-semiannular transition duct, named tdl18, that was conventionally shorter than previous duct designs. A numerical study of the flow through this duct was done by them. Some small transverse flow vortices and significant circumferential distortion were predicted by this study. No separated flow was predicted. Results from experimental tests of the td 118 duct are described in this paper.

The authors of this paper, prior to conducting the experiments documented here, completed a similar study on a duct nearly identical to the one described in this paper. ${ }^{4}$ That duct was made of a plastic material using a rapid prototyping stereo lithography process. There are some differences between the data from that plastic duct and the data presented here. The duct used in this study, which was milled from aluminum, more accurately represents Anderson and Kapoor's ${ }^{3}$ td 118 design than the plastic duct, hence, the data reported here are more reliable.

The objective of the research described in this paper is to provide a detailed set of experimental data to guide designers of diffusing rectangular-to-semiannular transition ducts by providing a benchmark data set comparing computational results.

Data presented include two-dimensional velocity vectors at the exit plane, total pressure recovery, surface static pressures, and surface oil flow visualization. The ability of vortex generators to reduce the amount of circumferential distortion is also presented.

\section{Experimental Facilities}

\section{Test Facility}

The experiment was conducted at the NASA Lewis Research Center using the Internal Fluid Mechanics Facility (IFMF). A schematic drawing of the facility can be seen in Fig. 2. Several previous duct studies have been conducted using this facility. ${ }^{5.6}$ Air was drawn directly from the test cell into a large settling chamber containing honeycombs and screens. From the settling chamber the air passed through a three-dimensional circular-to-square contraction having an area reduction ratio of 32 . From this contraction the fluid

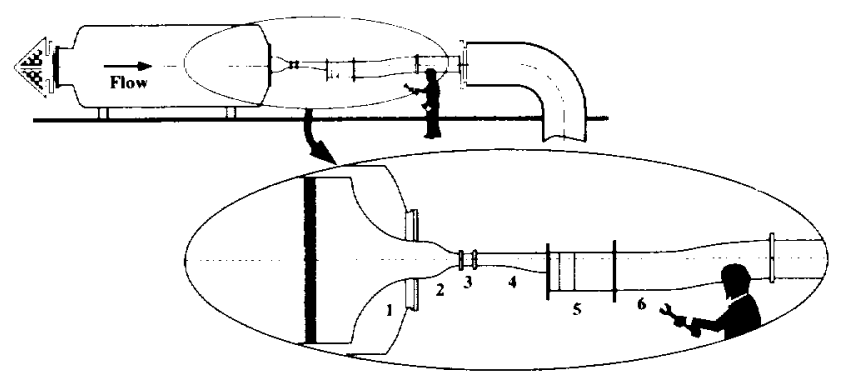

Fig. 2 Schematic of internal fluid mechanics facility: 1, circular to square contraction; 2 , converging nozzle; 3 , cross section duct; 4, TD118 HSR diffuser; 5, AIP instrumentation duct; and 6, flexible stainless-steel hose.
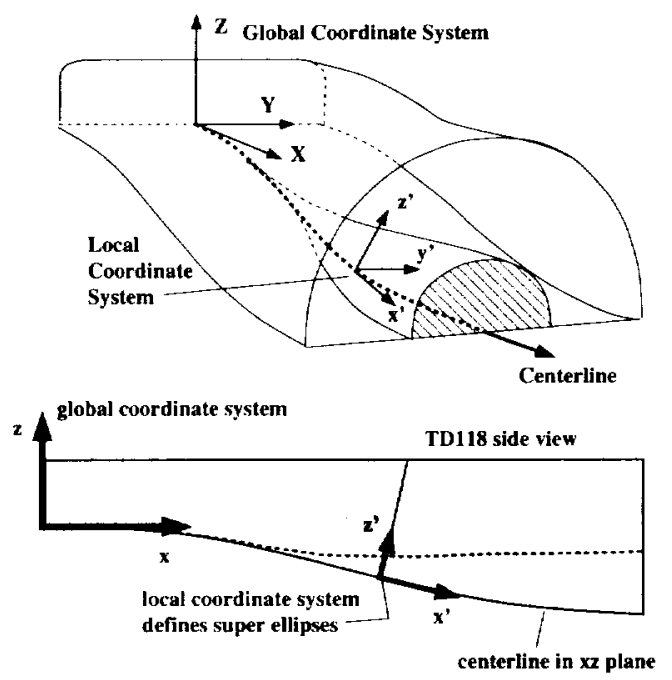

Fig. 3 Rectangular-to-semiannular transition duct td118.

passed through a square-to-rectangular nozzle having an area reduction ratio of 5 . The flow then moved through a transition piece that changed cross section from sharp corners to filleted corners before entering the test duct. From the test duct the flow went through the aerodynamic interface plane (AIP) instrumentation duct, a flexible steel hose, and was exhausted to a discharge plenum that was continuously evacuated by a central exhauster. Details on the IFMF can be found in Porro et al. ${ }^{7}$ Details on the modifications made for this series of tests can be found in Foster et al. ${ }^{4}$

\section{Rectangular-to-Semiannular Transition Duct}

The duct used for this study is shown in Fig. 3. As mentioned earlier, this transition duct was designed by Anderson and Kapoor ${ }^{3}$ for their computational study. Because of this, the duct's entrance is not truly a rectangle. The corners of the entrance to the duct are slightly rounded to provide the smooth boundary conditions necessary for some computational fluid dynamics methods. The equation that determines the upper surface of the duct is as follows:

$$
\left(\frac{y^{\prime} / R}{a_{0}}\right)^{n}+\left(\frac{z^{\prime} / R}{b_{0}}\right)^{n}=1
$$

The coordinates $x^{\prime}, y^{\prime}$, and $z^{\prime}$ are perpendicular to a centerline curve defined by the parametric equations

$$
\begin{aligned}
& X / R=\sum_{n=0}^{5} C_{0 . n} \tau^{n} \\
& Y / R=\sum_{n=0}^{5} C_{1 . n} \tau^{n} \\
& Z / R=\sum_{n=0}^{5} C_{2 . n} \tau^{n}
\end{aligned}
$$

where the global coordinates $(X, Y, Z)$ have an origin at the center bottom of the inlet of the duct. The duct was machined out of aluminum. The top and bottom surfaces were produced separately and bolted together.

\section{AIP Instrumentation Duct}

The AIP instrumentation duct was located immediately downstream of the transition duct. Its flow path was semiannular, just like the outlet of the transition duct. The hub-to-tip ratio of the AIP duct was 0.4 .

Two rakes of five-hole probes were in the AIP. These rakes were rotatable circumferentially. 
To seal the joint between the rotating rings and stationary portions of the duct, Teflon ${ }^{\text {tape }}$ was placed into the moving joints. Also, an O-ring was placed on the outside of the duct.

\section{Experimental Methods and Results}

All of the results presented in this section are nondimensional. Total pressure is represented as a ratio of the local total pressure and the reference total pressure at the inlet of the diffuser. Static pressure is presented as a static pressure coefficient. Velocity is presented as a ratio of the local velocity to the plane average velocity:

$$
\begin{gathered}
C_{p \mathrm{v}}=p_{0} / p_{0, \mathrm{cl}} \\
C_{p}=\left(p-p_{\mathrm{cl})}\right) /\left(p_{0 . \mathrm{cl}}-p_{\mathrm{cl}}\right) \\
\boldsymbol{v}=V / U_{\mathrm{av}}
\end{gathered}
$$

The reference states are defined as the inlet centerline conditions $p_{0, \mathrm{c} 1}$ and $p_{\mathrm{c} 1}$.

Total pressure distortion is reported using the methods outlined in the Society of Automotive Engineers (SAE) Aerospace Recommended Practices (ARP) report 1420. ${ }^{\mathrm{g}}$ The benefit of this method is its generality. The quantities calculated to describe total pressure distortion were intensity, extent, and multiple-per-rev value. The intensity describes the magnitude of the distortion. The extent describes the area covered by a low-pressure region, and the multiple-per-rev value describes the number of low-pressure regions there are in one 360-deg revolution. Each of these values were calculated for each circumferential ring of data taken. The maximum value of the product of the intensity and the extent were taken as the characteristic distortion quantity for each case reported. The equations used to calculate these values were

$$
\text { Intensity }=\left(\frac{\Delta P C}{P}\right)=\frac{(\mathrm{PAV})_{i}-(\mathrm{PAVLOW})_{i}}{(\mathrm{PAV})_{i}}
$$

where

$$
(\text { PAV })_{1}=\frac{1}{360} \int_{0}^{360} P(\theta) \mathrm{d} \theta
$$

PAV is the average total pressure on a circumferential ring and PAVLOW is the average total pressure for a low-pressure region. $P(\theta)$ is defined as a linear fit equation between data points. Distortion extent is defined as follows:

$$
\text { extent }=\theta_{i}^{-}=\sum_{k=1}^{Q} \theta_{i k}
$$

As shown in Fig. 4, $\theta_{i}=\theta_{2 i}-\theta_{1 i}$ and

$$
(\mathrm{MPR})_{i}=\sum_{k=1}^{A}\left[\left(\frac{\Delta P C}{P}\right)_{i k} \theta_{i k}\right] / \max \left[\left(\frac{\Delta P C}{P}\right)_{i k} \theta_{i k}\right]
$$

where MPR = multiple-per-rev distortion parameter. Example values can be seen in Fig. 4.

To explain where various flow phenomena occur in the diffuser, the three distinct surfaces in the diffuser will be referred to as the ramp, centerbody, and cowl. The ramp is the portion of the lower surface of the diffuser that has only two-dimensional curvature. The centerbody is the axisymmetric portion of the lower surface of the diffuser that is faired into the hub of the compressor. The cowl is the upper surface of the diffuser. These three surfaces can be seen in Fig. 5.

\section{Measurement Techniques}

The primary measurements taken for this study were AIP surveys of the time-averaged three-dimensional velocity com-

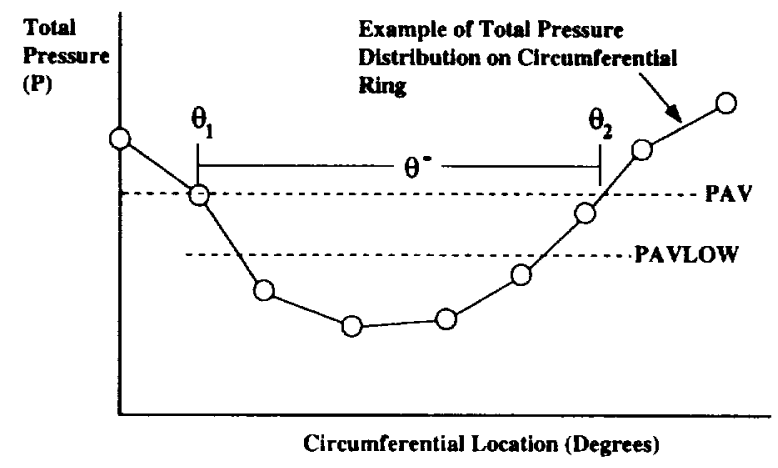

Fig. 4 Example values used in distortion calculation.

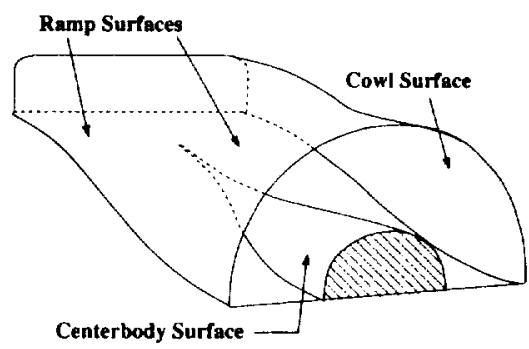

Fig. 5 Definition of surfaces within the duct.

ponents and the time-average total pressures. These measurements were made using two five-hole probe rakes. Each rake held three independently calibrated five-hole probe tips. The measurements were taken at intervals $\Delta r / D=0.016$ in the radial direction, and $\Delta \phi=5 \mathrm{deg}$ in the circumferential direction. The probes were calibrated and used in the same manner as described in Reichert and Wendt."

Surface static pressure measurements were also taken. The static taps were located in three lines that ran the axial length of the diffuser and in three circumferential planes. The axial lines were along the centerline of the cowl, the centerline of the ramp and centerbody, and along a line on the ramp at a distance of $0.4 R$ from the centerline.

The other measurement technique used was surface oil flow visualization. Using this technique the near-surface flow patterns could be observed. The flow pattern observed was recorded both by photography and by transferring the fluorescent oil to blotter paper by placing the paper on the duct surface and allowing it to absorb the fluorescent oil.

\section{Test Conditions}

Test inlet flow conditions were obtained $0.6 R$ upstream of the inlet of the diffuser. Boundary-layer measurements were taken with a pitot probe having a 0.010 -in.-diam tip. The boundary layer was fully turbulent. All tests were conducted at an inlet centerline Mach number of 0.786 . The $R e$, based on inlet width and centerline velocity, was $3.2 \times 10^{6}$. The inlet flow conditions are summarized in Table 1.

A series of five-hole probe measurements were also taken at the inlet plane. These confirmed that the cross-stream velocities were negligible at the inlet of the diffuser. The inlet conditions differ from those used by Anderson and Kapoor. ${ }^{3}$ They had a $R e$ of $2.4 \times 10^{6}$ and a boundary-layer height of $\delta / D \times 100=1.20$.

\section{Baseline Case}

Surface Oil Flow Visualization

A tracing of the streaklines from surface oil-flow visualization can be seen in Fig. 6. The streaklines on the ramp show a large area of relatively stagnant flow near the center of the ramp. However, no areas of reverse flow are seen. This area of stagnant flow appears around $x / D=0.7$ and continues to an 
Table 1 Inlet flow conditions

\begin{tabular}{lc}
\hline \hline Variable & Value \\
\hline$M_{\text {cl }}$ & 0.784 \\
$R e_{\text {cl }}$ & $3.2 \times 10^{6}$ \\
$(\delta / D) \times 100$ & 0.800 \\
$\left(\delta_{1} / D\right) \times 100$ & 0.135 \\
$\left(\delta_{2} / D\right) \times 100$ & 0.089 \\
$H$ & 1.52 \\
\hline
\end{tabular}

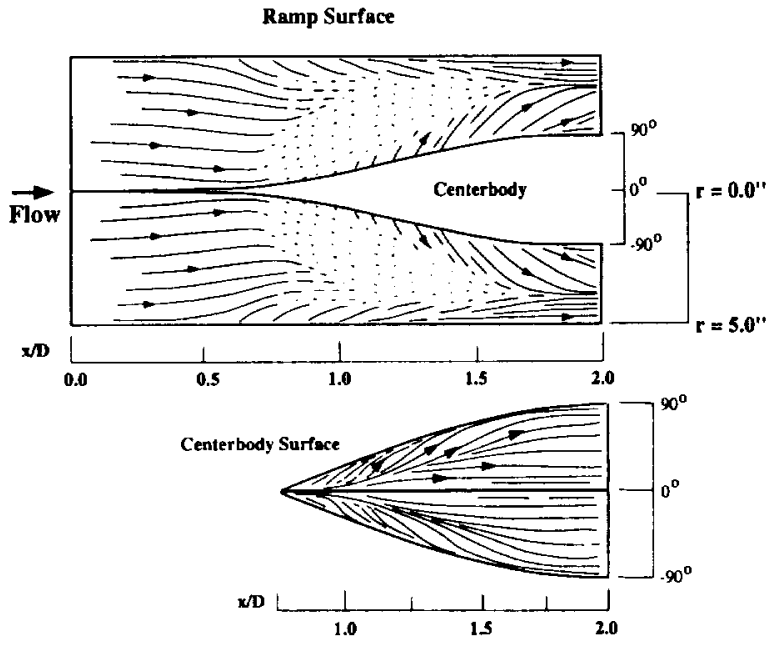

Fig. 6 Surface oil-flow visualization.

axial location of $x / D=1.6$. After that axial location no stagnant flow is apparent. However, strong crossflows away from the center of the duct are seen. These are the result of the centerbody increasing in size. This steers flow away from the center of the duct.

\section{Surface Static Pressure Measurements}

The axial distribution of static pressure is shown in Fig. 7. Initially, static pressure on the cowl is slightly higher than that on the ramp or centerbody. At $x / D=0.6$ the cowl has a lower static pressure than the other surfaces. This corresponds to the same axial position where stagnant flow streaklines were observed by surface oil flow visualization. As the centerbody increases in size, the static pressure along the centerline of the centerbody also increases. The higher static pressure on the centerline of the centerbody could be responsible for the surface oil streaklines pointing away from the centerline of the centerbody from an $x / D=1.0-1.5$. After $x / D=1.5$ those streamlines appear to return to a streamwise direction, which corresponds to the relatively lower centerline pressure at that point.

The cowl static pressure distribution seems to be in general agreement with the computational results of Anderson and $\mathrm{Ka}$ poor. ${ }^{3}$ The fact that there is some divergence between the computed and measured data around $x / D=0.7$ suggests that the stagnant flow seen in the surface flow visualization causes the boundary layer to grow faster than predicted by the computations.

\section{Five-Hole Probe Data}

The total pressure distribution in the exit plane is shown in Fig. 8. The curvature of the ramp was responsible for the large areas of low total pressure that can be seen on either side of the centerbody. The other area with large total pressure loss is the center of the cowl. The area-averaged total pressure recovery was $p_{0} / p_{\text {ref }}=0.957$. The distortion was characterized by an intensity of 0.059 , an extent of $60 \mathrm{deg}$, and a MPR value of 2.0 .

The transverse velocity components in the exit plane are shown in Fig. 9. The results are symmetric. The most pro-

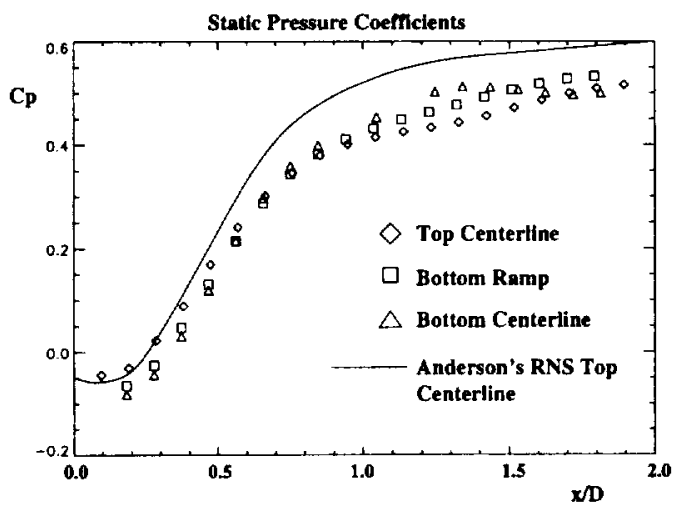

Fig. 7 Surface static pressure measurements.

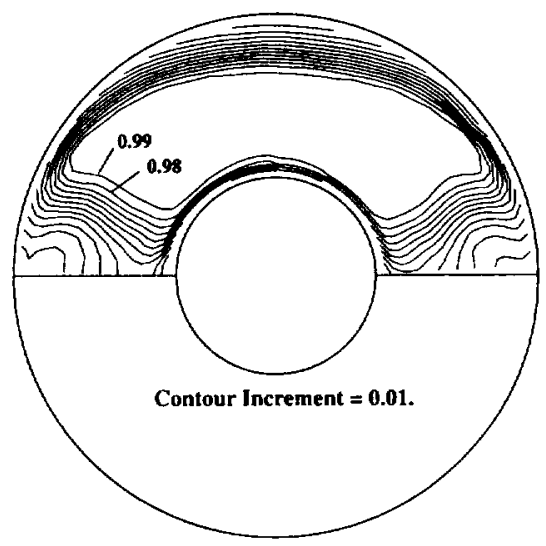

Fig. 8 Exit plane total pressure contours.

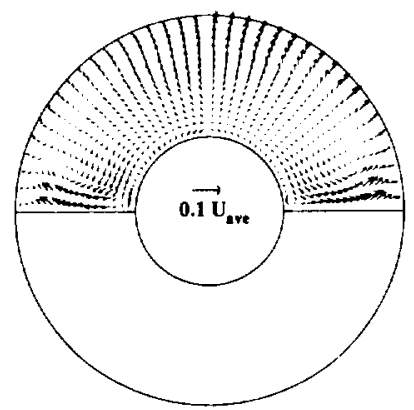

Fig. 9 Transverse velocity components.

nounced feature of the flow is that the vectors are pointed away from the centerbody toward the cowl. These vectors combined with the ramp surface crossflows indicate that a large amount of fluid was being pushed away from the centerline of the duct toward the center of the ramp. This could be the reason that the total pressure recovery near the centerbody is larger than near the cowl.

Comparison with the work by Anderson and Kapoor ${ }^{3}$ shows that there is good agreement between the computational and experimental results for the flow at the exit of the diffuser.

\section{Vortex Generator Case}

Vortex generators have been used effectively to improve total pressure recovery and distortion in many subsonic ducts, even in the absence of flow separation, such as was demonstrated by Brown et al ${ }^{1}$ and Reichert and Wendt. ${ }^{10}$ In an attempt to improve the tdl18 duct's performance, two pairs of corotating vortex generators were placed on the cowl surface and two sets of corotating vortex generator pairs were placed on the ramp surface on either side of the centerbody. These locations were chosen based on the surface oil-flow visualiza- 

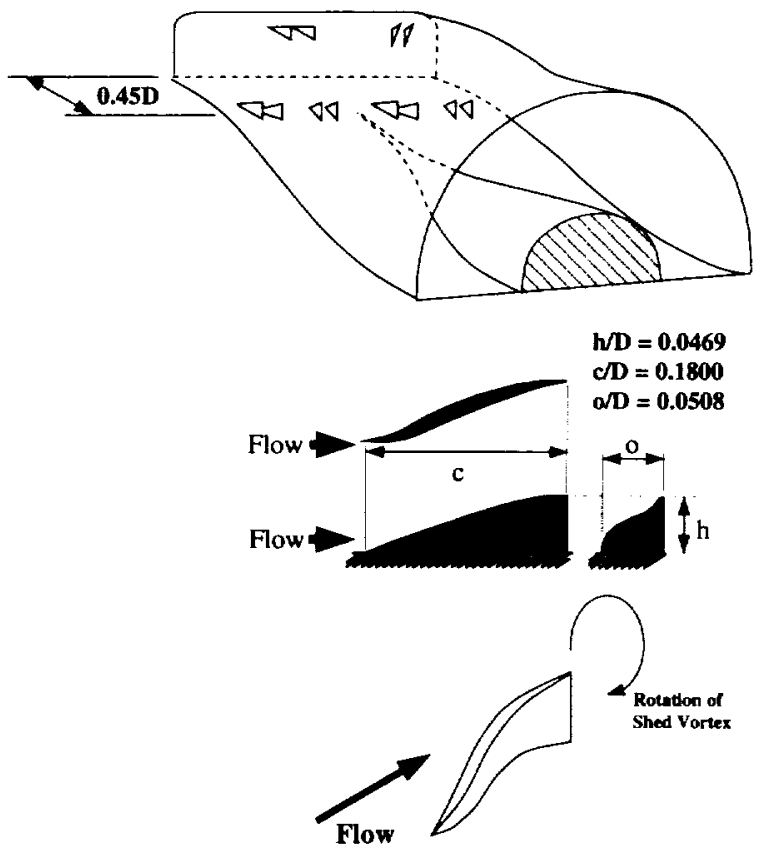

Fig. 10 Vortex generator size and placement.

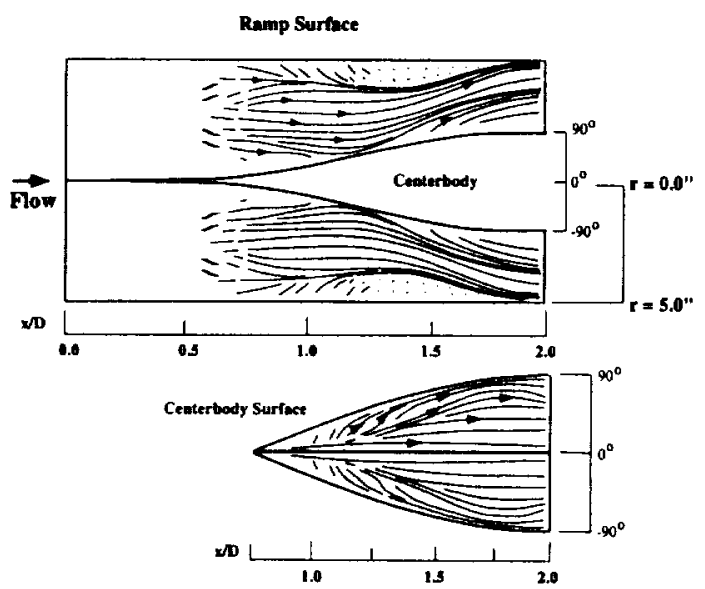

Fig. 11 Surface oil-flow visualization.

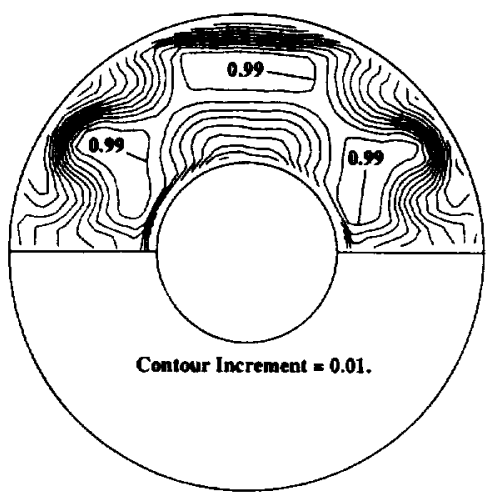

Fig. 12 Total pressure contours for vortex generator case.

tion, and based on the areas in the exit plane pressure contour plot that had low total pressure recovery. A sketch of the vortex generator placement can be seen in Fig. 10.

Surface Oil-Flow Visualization

Figure 11 shows the surface oil-flow visualization data from the ramp and centerbody surfaces with vortex generators used.

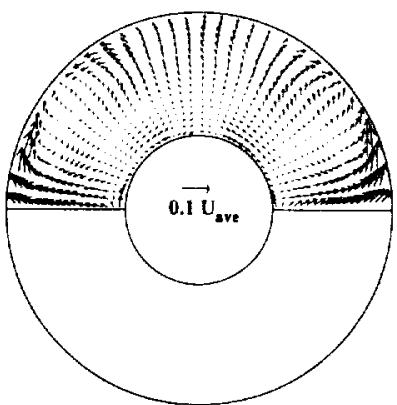

Fig. 13 Transverse velocity components for vortex generator case.

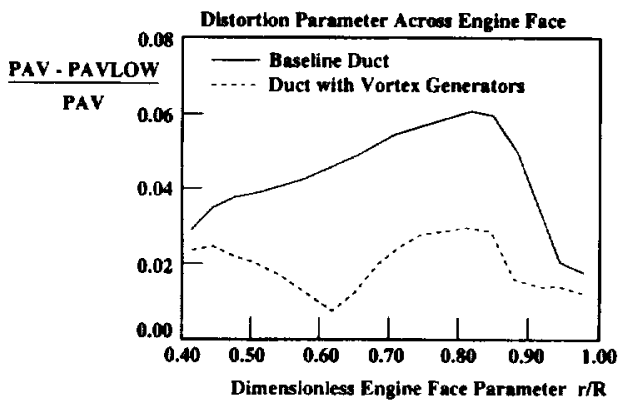

Fig. 14 Comparison of distortion intensities.

The vortex generator array almost completely eliminated the region of stagnant flow on the ramp surface. Near the exit of the duct, from $x / D=1.5-2.0$, the effect of the centerbody diameter increasing can be seen as the streamlines bend away from the centerbody toward the cowl wall.

\section{Five-Hole Probe Data}

In Fig. 12, the total pressure contours show a larger area of low momentum fluid near the centerline above the centerbody surface. This is most likely caused by the vortex created by the vortex generator pushing lower momentum boundary-layer fluid up the centerbody surface. The velocity vectors shown in Fig. 13 also show that fluid is moving up the surface of the centerbody toward the centerline of the duct. However, this area of higher losses is offset by lower losses near the cowl surface and the ramp. On the cowl the vortex generators steered the low momentum fluid away from the centerline, reducing the size of the low total pressure area seen in Fig. 8 near the centerline of the cowl surface.

Similarly, the vortex generators on the ramp surface are responsible for drawing the region of high total pressure recovery down very near the ramp surface, by steering low-momentum fluid away from the center of the ramp and drawing higher momentum fluid from the mean flow toward the ramp surface. This can be seen in Fig, 12 in the area near the ramp centerbody intersection.

The area-averaged total pressure recovery for this case is 0.956 . The total pressure distortion is characterized by an intensity of 0.026 , an extent of $67 \mathrm{deg}$, and a MPR value of 2.3 .

These distortion parameters can be used as a tool to better understand the effect of the vortex generators on the pressure recovery. A plot of the distortion intensity for each radial ring from $r / R=0.42-0.98 \mathrm{can}$ be seen in Fig. 14. This shows that while the area-averaged total pressure did not change significantly with the use of vortex generators, the total pressure losses were more evenly distributed along any given circumferential ring.

\section{Summary}

Rectangular-to-semiannular transition ducts are an integral part of the propulsion system for any aircraft utilizing bifur- 
cated inlets. Because of the shape of the flowpath, the total pressure distortion is quite large. This is because of areas of low total pressure near the ramp and cowl surfaces at the exit of the duct. This distortion can be reduced by use of vortex generators; however, for the configuration studied here, vortex generators reduced total pressure distortion, but did not improve the total pressure recovery of the duct.

\section{Acknowledgments}

This research was carried out under NASA Grant NAG21561. We would especially like to acknowledge the help of $B$. Darby, B. Erbar, B. Gronski, A. Sprungle, and D. Taggart. All of whom made very valuable contributions to this project.

\section{References}

'Brown, A. C., Nawrock, F. H., and Paley, P. N., "Subsonic Diffusers Designed Integrally with Vortex Generators," Journal of Aircraft, Vol. 3, No. 3, 1966, pp. 221-229.

${ }^{2}$ Wasserbauer, J., Mealson. E., and Burstadt, P., "Experimental Investigation of the Performance of a Mach 2.7 Two Dimensional Bifurcated Duct Inlet with 30 Percent Internal Contraction," NASA TM
106728, May 1996.

${ }^{3}$ Anderson, B., and Kapoor, K., "A Study on Bifurcated Transitioning S-Ducts for High Speed Inlet Application," AIAA Paper 942812, June 1994

${ }^{4}$ Foster, J. D., Okiishi, T. H., Wendt, B. J., and Reichert, B. A., "Study of Compressible Flow Through a Rectangular-to-Semiannular Transition Duct," NASA CR 4660, April 1995.

'Reichert, B. A., Hingst, W. R., and Okiishi, T. H., "An Experimental Comparison of Nonswirling and Swirling Flow in a Circularto-Rectangular Transition Duct," AIAA Paper 91-0342, Jan. 1991.

"Wellborn, S. R., Okiishi, T. H., and Reichert, B. A., "A Study of the Compressible Flow Through a Diffusing S-Duct," NASA TM 106411, Dec. 1993.

'Porro, A. R., Hingst, W. R., Wasserbauer, C. A., and Andrews, T. B. "The NASA Lewis Research Center Internal Fluid Mechanics Facility," NASA TM 105187, Sept. 1991.

8“Gas Turbine Engine Inlet Flow Distortion Guidelines," Society of Automotive Engineers, ARP 1420, March 1978.

${ }^{9}$ Reichert, B. A., and Wendt, B. J., "Uncertainty of Five-Hole Probe Measurements," Fluid Measurement and Instrumentation 1994, edited by T. B. Morrow, G. L. Morrison, and R. A. Gore, American Society of Mechanical Engineers, New York, 1994, pp. 39-44.

${ }^{10}$ Reichert, B. A., and Wendt, B. J.. "Improving S-Duct Performance by Secondary Flow Control," AIAA Paper 94-0365, Jan. 1994 
